\title{
Antinociceptive Activity of Methanol Extract of Dioscorea Pentaphylla Linn. Leaves in Mice
}

\author{
Towhidul Islam ${ }^{1}$, Anawara Begum ${ }^{1}$, Shahed-Al-Mahmud ${ }^{1,2, *}$ \\ ${ }^{1}$ Department of Pharmacy, Stamford University Bangladesh, Bangladesh \\ ${ }^{2}$ Department of Microbiology and Immunology, School of Medicine, Tzu Chi University, Taiwan
}

Copyright $(\mathrm{C} 2018$ by authors, all rights reserved. Authors agree that this article remains permanently open access under the terms of the Creative Commons Attribution License 4.0 International License

\begin{abstract}
Background: Dioscorea pentaphylla L. a common plant of Dioscorea family commonly called five leaves in Bangladesh. The plant contains the alkaloid, carbohydrate, tannin, gum protein, steroid, glycoside, flavonoids. It is used as an analgesic, anti-inflammatory, and Powder of plant extract given orally in abdominal pain after delivery. The aim of the study: The present study was designed to evaluate chemical constituents and to investigate the antinociceptive activity of methanol extracts of Dioscorea pentaphylla (MEDP). Methods: The antinociceptive activity of MEDP was investigated using heat-induced (hot-plate and tail-immersion test) and chemical-induced (acetic acid, Formalin-induced) nociception models in mice at $200 \& 400 \mathrm{mg} / \mathrm{kg}$ doses. Result: Oral administration of the methanolic extract of leaves of Dioscorea pentaphylla L. (200 \& $400 \mathrm{~kg} / \mathrm{mg}$ ) dose-dependently reduced nociceptive response to acute pain in acetic acid induced writhing. For acetic acid-induced writhing test highest inhibition $(55.40 \%)$ was found in case of highest dose $(400 \mathrm{mg} / \mathrm{kg})$ for leaf extract. Whereas standard drug diclofenac sodium causes $(46.93 \%)$ writhing inhibition. Formalin-induced nociception test showed the significant effect in $(200$ and $400 \mathrm{mg} / \mathrm{kg}$ ) for both dosages. On the other hand, MEDP showed the significant effect in hot plate, tail immersion test, at high dose $(400 \mathrm{mg} / \mathrm{kg})$. Conclusion: MEDP showed significant antinociceptive activity via a multifactorial mechanism of action, indicating that the extract may be useful in the development of a new analgesic drug.
\end{abstract}

Keywords: Dioscorea pentaphylla, Dioscorea, Antinociceptive, Pain, Hot Plate Test, Tail Immersion Test.

\section{Introduction}

Pain is one of the most important health problems because of its prevalence and the disabilities. It is believed that acute pain serves as alarm and deserves to protect the organism against noxious stimuli, while chronic pain, in contrast, is an entire disease and may result from tissue injuries. Indeed, chronic pains may be a consequence of sustained inflammatory diseases or tissue damages such as nerve injury in the case of neuropathic pain. Chronic pain affects about $17-45 \%$ of the population and it is believed that the same range or even more may be found in developing countries where the population cannot afford manufactured drugs. Moreover, chronic pain is often resistant to existing therapy. So, there is a great need to search for new and better drugs.

Medicinal plants are largely used worldwide by the population and have proved to be a rich source of new active compounds, especially to treat pain and inflammatory processes. Dioscorea yam is a member of the Yam family [1]. The yams are vining plants with 600 known species, 71 of which are native to North America (67 species in Mexico) [2]. It is native to Southeast Asia and is distributed throughout India, China, and southwards from Malaysia to Australia. In many species of yam, the rhizome (tuber) serves as both food and medicine [3]. Many native Americans and South Asians used a syrup of the root to relieve labor pain and later physicians gave wild yam to patients with colic pain, morning sickness, asthma, hiccough, rheumatism and gastritis related to alcoholism [4]. Modern herbalists value wild yam to treat intestinal colic, biliary colic, and flatulence as well as menstrual cramps and rheumatoid arthritis [5]. Herbalists combine wild yam with black cohosh (and sometimes burdock root and motherwort) for rheumatic complaints. Chinese herbalists use wild yam as a tonic [6]. The decoction of the tuber is given to animals for early recovery of fractured bones. The raw tuber is given to cattle to cure Diphtheria. Cough, cold, asthma, tuberculosis [7].

It has reported that Dioscorea species contains steroidal saponin, spiroconazole A, a phenanthrene, 2,7dihydroxy-4-methoxyphenanthrene, flavonoids as quercetin, quercetin-3-O- $\beta$-D-glucopyranoside, and quercetin-3-O- $\beta$-D-galactopyranoside, and seven clerodane diterpenoids namely, bafoudiosbulbins A, B, C, 
$\mathrm{D}, \mathrm{E}, \mathrm{F}$, and $\mathrm{G}$ have been isolated from the methanol extract of the bulb of Dioscorea bulbifera var sativa [8]. Due to the lack of knowledge, we designed the present investigation in methanolic extract of $D$. pentaphylla. In this paper, we describe the chemical and heat induced antinociceptive activity of wild yams $D$. pentaphylla in mice model.

\section{Materials and Methods}

\subsection{Plant Collection and Identification}

Dioscera pentaphylla leaves collected during November, 2015 from the Jahangir Nagar University campus savar, Dhaka, Bangladesh. The plant's leaves verification done by the senior scientific officer of National Herbarium, Mirpur, Dhaka, Bangladesh. Additionally, the voucher specimen number (Accession No. 42052) deposited for further reference.

\subsection{Preparation of Plant Extract}

The Powdered leave of $D$. pentaphylla of about $400 \mathrm{~g}$ was taken in a clean and flat-bottomed glass beaker and soaked in $5000 \mathrm{~mL}$ methanol (Merck, Germany). The solvent extraction of plant leaves powder stirred at $25 \pm 2$ ${ }^{\circ} \mathrm{C}$ for 5 days. The solvent mixture filtrated by a piece of sterile and white cotton material and finally using Whatman No. 1 filter paper. The solvent completely removed by the operation of the rotary evaporator (BC-R 201 Shanghai Biochemical Equipment Co. Ltd.) and obtained $30.07 \mathrm{~g}$ extract (Yield 75.78\%). The prepared extract used for the phytochemical screening as well as antinociceptive studies.

\subsection{Chemicals and Drugs}

The following chemicals and drugs in our recent study: Acetic acid (Merck, Germany), methanol (Merck, Germany), formalin (Merck, Germany), morphine sulfate (Gonoshasthaya pharmaceuticals Ltd ) and diclofenac sodium (Square Pharmaceuticals Ltd., Bangladesh). MEDP at the doses of 200 and $400 \mathrm{mg} / \mathrm{kg}$ dissolved in double distilled water and administered orally 30 minutes before to the test. The standard drug morphine sulphate 5 $\mathrm{mg} / \mathrm{kg}$ (Manufactured by Square Pharmaceuticals Ltd., Bangladesh) used in hot-plate and tail immersion pain models. Diclofenac sodium $10 \mathrm{mg} / \mathrm{kg}$ (Square Pharmaceuticals Ltd., Bangladesh) used in writhing and licking tests prepared with saline water (containing $0.9 \%$ $\mathrm{NaCl}$ ) which administered intraperitoneally 15 minutes before the experiments. The control group received saline water (containing $0.9 \% \mathrm{NaCl}$ ) $0.1 \mathrm{~mL} /$ mouse 30 minutes before the experiments.

\subsection{Experimental Animals}

Swiss albino mice (20-25 g) collected from the Animal Research Branch of the International Center for Diarrheal Disease and Research, Bangladesh (ICDDR, B). The animal kept under standard laboratory conditions as well as maintained room temperature, relative humidity: $55-65 \%$, $12 \mathrm{~h} \mathrm{light/dark} \mathrm{cycle} \mathrm{with} \mathrm{standard} \mathrm{diet} \mathrm{and} \mathrm{clean} \mathrm{water} \mathrm{ad}$ libitum during the adaption period. The mice fasted overnight before the experiments. We followed Ethical Principles and Guidelines for mice observations which provided by Scientific Experiments on Animals (1995). This guideline created by Swiss Academy of Medical Sciences and Swiss Academy of Science. Our research program approved by the Institutional Animal Ethical Committee (SUB/IAEC/ 15.04) of Stamford University Bangladesh.

\subsection{Phytochemical Screening}

The crude methanol extract of $D$. pentaphylla leaves qualitatively tested for the detection of alkaloids, glycosides, flavonoids, tannins, reducing sugar, carbohydrates, steroids and saponins following standard procedures [9].

\subsection{Measurement of Antinociceptive Activity}

\subsubsection{Hot Plate Test}

The hot plate test (Heat-induced pain) performed to measure the possible nociceptive response using Eddy's hot plate apparatus [10]. Experimental mice divided into five groups $(n=10)$. Each mouse of the control group treated with saline water $(0.9 \% \mathrm{NaCl} ; 0.1 \mathrm{~mL} /$ mouse $)$ and the positive control group received morphine $(5 \mathrm{mg} / \mathrm{kg}$, i.p.) as a reference drug or MEDP (200, and $400 \mathrm{mg} / \mathrm{kg}$, p.o.). During observation Eddy's hot plate metal surface temperature maintained at $52 \pm 2^{\circ} \mathrm{C}$. The doses of MEDP administered 30 minutes before the experimental observation while reference drug as positive control (morphine sulphate $5 \mathrm{mg} / \mathrm{kg}$, i.p.) administered 15 minutes before the experimental observation. The nociceptive response in the form of fore paw licking, withdrawal of the paws or jumping was recorded at $0,15,30,45$, and 60 minutes of the following treatment. A cut-off period of the 20 seconds was maintained to avoid paw tissue damage. The hot plate experimental value expressed as the maximal possible effect (\%MPE), [11] which was calculated using the following formula:

$\% \mathrm{MPE}=[($ Post drug latency $)-($ Pre drug latency $) /$ (Cut-off time) - (Pre drug latency)] $\times 100$.

\subsubsection{Tail Immersion Test}

Tail immersion test (Heat-induced pain) in mice is performed to determine the central mechanism of analgesic 
activity according to the method described by [12]. The antinociceptive response based on particularly the morphine-like drug selectively prolongs the typical tail withdrawal reflex in mice. The painful reaction consider as the tail dipping into the hot water which produced by thermal incentive. During experimental observation 1 to 2 $\mathrm{cm}$ of the tail of mice allowed to immerse warm water bath kept constant at $52 \pm 11^{\circ} \mathrm{C}$. Experimental mice divided into five groups $(\mathrm{n}=10)$. Each mouse of the control group treated with saline water $(0.9 \% \mathrm{NaCl} ; 0.1 \mathrm{~mL} /$ mouse $)$ and the positive control group received morphine ( $5 \mathrm{mg} / \mathrm{kg}$, i.p.) as a reference drug or MEDP (200, and $400 \mathrm{mg} / \mathrm{kg}$, p.o.). During observation Eddy's hot plate metal surface temperature maintain at $52 \pm 2^{\circ} \mathrm{C}$. The doses of MEDP administered 30 minutes before the experimental observation while reference drug as positive control (morphine sulphate $5 \mathrm{mg} / \mathrm{kg}$, i.p.) administered 15 minutes before the experimental observation. The nociceptive response in the form of fore paw licking, withdrawal of the paws or jumping was recorded at $0,15,30,45$, and 60 minutes of the following treatment. A cut-off period of the 20 seconds was maintained to avoid paw tissue damage. The \%MEP was calculated by the same formula used in hot plate test.

\subsubsection{Acetic Acid-induced Writhing Test}

The peripheral antinociceptive response of MEDP measured by acetic acid-induced test (Chemical-induced pain). Experimental mice divided into five groups $(\mathrm{n}=10)$. Each mouse of the control group treated with saline water $(0.9 \% \mathrm{NaCl} ; 0.1 \mathrm{~mL} /$ mouse $)$ and the positive control group received Diclofenac sodium $(10 \mathrm{mg} / \mathrm{kg}$, i.p. $)$ as a reference drug or MEDP (200, and $400 \mathrm{mg} / \mathrm{kg}$, p.o.). The doses of MEDP administered 30 minutes whereas, the reference drug as positive control (diclofenac sodium $10 \mathrm{mg} / \mathrm{kg}$, i.p.) administered 15 minutes before $0.7 \%$ acetic acid injection [13]. The writhing observation has done after 5 minutes of acetic acid injection. The visualization cue of each writhing appeared like strong abdominal muscle contractions, followed by trunk twisting and extension of the hind limbs as well as contact of the abdomen with the floor considered as complete writhing. Antinociceptive response expressed as writhing inhibition (\%) and calculated by using the following formula:

Writhing inhibition $(\%)=[(\mathrm{Wc}-\mathrm{Ws}) / \mathrm{Wc}] \times 100$,

Where, Wc is the mean number of writhing of control and Ws is the mean number of writhing of the test sample.

\subsubsection{Formalin-induced Paw Licking Test}

The formalin-induced nociception response observed according to licking of hind paw [14]. Each mouse of the control group treated with physiological saline water $(0.9 \%$ $\mathrm{NaCl} ; 0.1 \mathrm{~mL} /$ mouse) and the positive control group received Diclofenac sodium $(10 \mathrm{mg} / \mathrm{kg}$, i.p. $)$ as a reference drug or MEDP (200, and $400 \mathrm{mg} / \mathrm{kg}$, p.o.). The doses of MEDP administered 60 minutes whereas, the reference drug as positive control (diclofenac sodium $10 \mathrm{mg} / \mathrm{kg}$, i.p.) administered 15 minutes before $20 \mu \mathrm{l}$ of $2.5 \%$ formalin made up in saline water. The formalin injected subcutaneously in the right hind paw of each mouse by the 30 -gauge needle. The licking and biting considered as the nociceptive response which recorded for 5 minutes during formalin injection. Formalin-induced licking behavior determined the initial phase (First phase, neurogenic) 0-5 minutes whereas, late phase (Second phase, inflammatory) 15-30 minutes [15]. Antinociceptive activity calculated as the percentage of licking time inhibition.

\section{Results}

\subsection{Phytochemical Screening}

Preliminary phytochemical screening of the crude extract of $D$. pentaphylla revealed the presence of alkaloids, glycosides, flavonoids, tannins, steroids and saponins.

\subsection{Measurement of Antinociceptive Activity}

\subsubsection{Hot plate test}

The antinociceptive activity of MEDP at the doses (200, and $400 \mathrm{mg} / \mathrm{kg}$ ) in hot plate significantly $(p<0.001)$ increased the reaction time to the thermal stimulus and the antinociceptive effects was dose-dependent (Figure 1). The standard drug morphine sulphate showed highest \%MPE values at all the observation periods 15 to 60 minutes (Table 1).

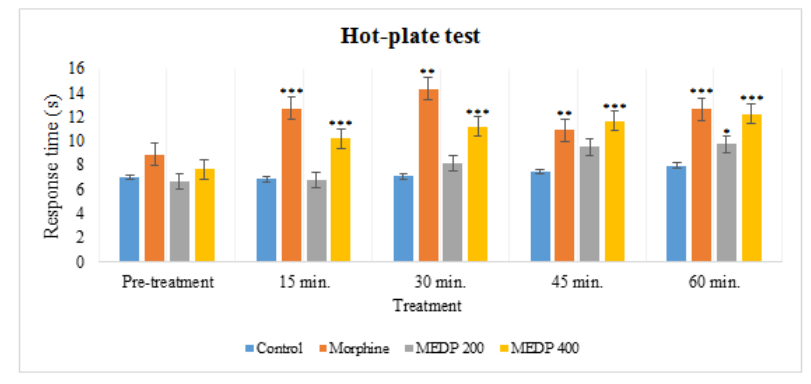

Figure 1. Antinoceciptive effect of D. pentaphylla leaves extract and morphine in hot plate test.

\subsubsection{Tail immersion test}

The antinociceptive activity of MEDP at the doses (200, and $400 \mathrm{mg} / \mathrm{kg}$ ) in tail immersion test significantly increased the latency period to hot-water induced thermal stimuli $(p<0.001)$ and the antinociceptive effects was dose-dependent (Figure 2). The standard drug morphine sulphate showed highest \%MPE values at all the observation periods 15 to 60 minutes (Table 2). 


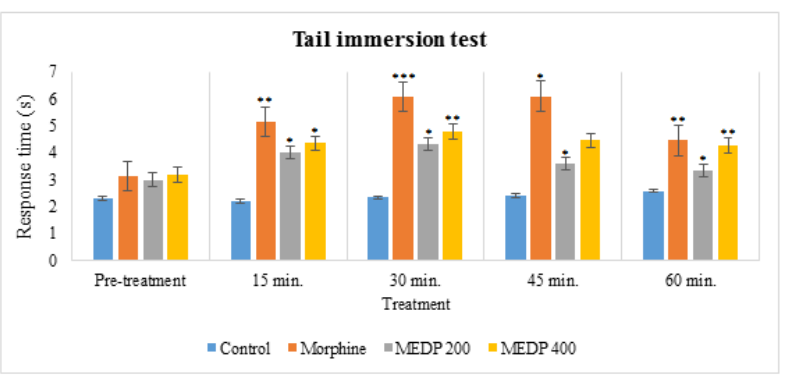

Figure 2. Antinoceciptive effect of $D$. pentaphylla leaves extract and in tail immersion test.

\subsubsection{Acetic acid-induced writhing test}

The oral administration of MEDP at 200, and $400 \mathrm{mg} / \mathrm{kg}$ doses significantly $(p<0.001)$ reduced the writhing episodes which induced by acetic acid compared with the control group (Figure 3). The percentage inhibition of abdominal contraction demonstrated the antinociceptive activity. Diclofenac sodium as the standard drug, inhibited $46.39 \%$ writhing in comparison to the control group. MEDP showed very strong writhing inhibitory effect at $400 \mathrm{mg} / \mathrm{kg}$ which value close to the effect like diclofenac sodium $(55.40 \%)$. MEDP at the dose of $200 \mathrm{mg} / \mathrm{kg}$ also produced antinociceptive activity $28.37 \%$ (Table 3 ).

\subsubsection{Formalin-induced paw licking test}

The antinociceptive effect of MEDP at the doses of 200, and $400 \mathrm{mg} / \mathrm{kg}$ caused a significant $(p<0.001)$ inhibition of the formalin-induced paw licking test when compared with the control group (Figure 4). The effects were dose-dependent inhibition of both neurogenic (0-5) minutes and inflammatory (15-30) minutes phases (Table
4). However, the antinociceptive effect was more precise in the second phase of this pain model. The nociception significantly reduced at 200 , and $400 \mathrm{mg} / \mathrm{kg}$ doses in late phase. Diclofenac sodium significantly $(p<0.001)$ reduced formalin-induced nociception in early phage $(71.67 \%)$ and late phage (96.11\%).

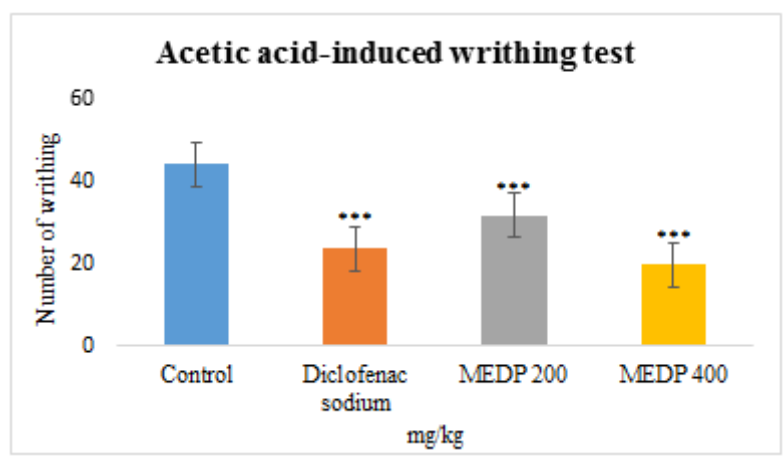

Figure 3. Antinoceciptive effect of $D$. pentaphylla leaves extract in acetic acid-induced writhing test in mice.

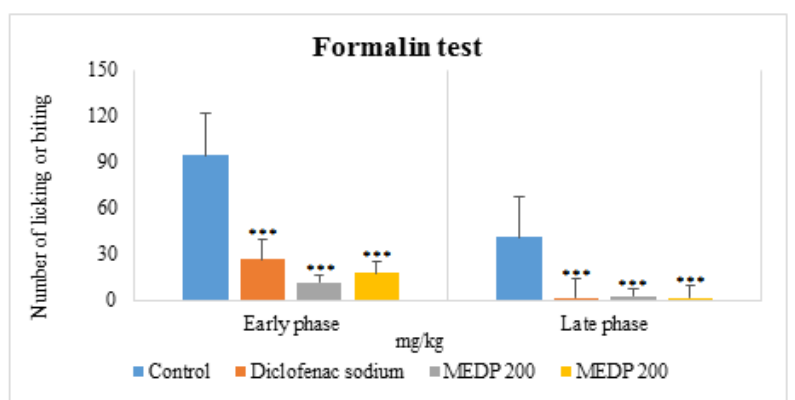

Figure 4. Antinoceciptive effect of $D$. pentaphylla leaves extract in formalin test in mice.

Table 1. Antinoceciptive effect of D. pentaphylla leaves extract and morphine in hot plate test.

\begin{tabular}{|c|c|c|c|c|c|c|}
\hline Treatment & Dose (mg/kg) & $\mathbf{0 ~} \mathbf{~ m i n}$ & $\mathbf{1 5} \mathbf{~ m i n}$ & $\mathbf{3 0} \mathbf{~ m i n}$ & $\mathbf{4 5} \mathbf{~ m i n}$ & $\mathbf{6 0} \mathbf{~ m i n}$ \\
\hline Control & $\begin{array}{c}0.1 \\
\mathrm{ml} / \mathrm{mouse}\end{array}$ & $7.00 \pm .316$ & $6.84 \pm .21$ & $7.09 \pm .10$ & $7.46 \pm .28$ & $7.98 \pm .31$ \\
\hline Morphine & 5 & $8.86 \pm .23$ & $12.67 \pm .76^{* * *}$ & $14.30 \pm 2.48^{* *}$ & $10.91 \pm .52^{* *}$ & $12.65 \pm .46^{* * *}$ \\
\hline MEDP & 200 & $6.67 \pm .16$ & $6.79 \pm .09$ & $8.16 \pm .42$ & $9.49 \pm .75$ & $9.72 \pm .36^{*}$ \\
\hline MEDP & 400 & $7.65 \pm .31$ & $10.23 \pm .31 * * *$ & $11.21 \pm .29 * * *$ & $11.63 \pm .39 * * *$ & $12.22 \pm .53^{* * *}$ \\
\hline
\end{tabular}

Each value is expressed as the mean $\pm \operatorname{SEM}(\mathrm{n}=10)$. MEDP $=$ Methanol extract of Dioscera pentaphylla leaves. ${ }^{*} p<0.05,{ }^{* *} p<0.01$ and $* * * p$ $<0.001$ compared with the control group (Dunnett's test).

Table 2. Antinoceciptive effect of $D$. pentaphylla leaves extract and in tail immersion test.

\begin{tabular}{|c|c|c|c|c|c|c|}
\hline Treatment & Dose (mg/kg) & $\mathbf{0} \mathbf{~ m i n}$ & $\mathbf{1 5} \mathbf{~ m i n}$ & $\mathbf{3 0 ~} \mathbf{~ i n}$ & $\mathbf{4 5} \mathbf{~ m i n}$ & $\mathbf{6 0} \mathbf{~ m i n}$ \\
\hline Control & $0.1 \mathrm{ml} /$ mouse & $2.31 \pm .14$ & $2.2 \pm .09$ & $2.34 \pm .33$ & $2.41 \pm .30$ & $2.59 \pm .067$ \\
\hline Morphine & 5 & $3.14 \pm .28$ & $5.16 \pm .38^{* *}$ & $6.08 \pm .38^{* * *}$ & $6.09 \pm .84^{*}$ & $4.46 \pm .22 * *$ \\
\hline MEDP & 200 & $3.00 \pm .34$ & $4.02 \pm .82^{*}$ & $4.34 \pm 1.49^{*}$ & $3.59 \pm .19$ & $3.34 \pm .19$ \\
\hline MEDP & 400 & $3.19 \pm .45$ & $4.36 \pm .18^{*}$ & $4.79 \pm .19 * *$ & $4.46 \pm .44^{*}$ & $4.27 \pm .29^{* *}$ \\
\hline
\end{tabular}

Each value is expressed as the mean $\pm \operatorname{SEM}(\mathrm{n}=10)$. MEDP $=$ Methanol extract of Dioscera pentaphylla leaves. $* p<0.05, * * p<0.01$ and $* * * p$ $<0.001$ compared with the control group (Dunnett's test). 
Table 3. Antinoceciptive effect of $D$. pentaphylla leaves extract in acetic acid-induced writhing test in mice

\begin{tabular}{|c|c|c|c|}
\hline Treatment & Dose (mg/kg) & Number of writhing & Inhibition (\%) \\
\hline Control & $0.1 \mathrm{ml} / \mathrm{mouse}$ & $44.4 \pm 1.77$ & $46.39 \%$ \\
\hline Diclofenac Sodium & 10 & $23.8 \pm 1.46^{* * *}$ & $28.37 \%$ \\
\hline MEDP & 200 & $31.8 \pm 1.59^{* * *}$ & $55.40 \%$ \\
\hline MEDP & 400 & $19.8 \pm 0.37^{* * *}$ & \\
\hline
\end{tabular}

Each value is expressed as the mean $\pm \operatorname{SEM}(\mathrm{n}=10) . \mathrm{MEDP}=$ Methanol extract of Dioscera pentaphylla leaves. $* p<0.001$ compared with the control group (Dunnett's test).

Table 4. Antinoceciptive effect of $D$. pentaphylla leaves extract in formalin test in mice.

\begin{tabular}{|c|c|c|c|c|}
\hline Treatment & Dose (mg/kg) & Early Phase (0-5)min & Inhibition (\%) & $\begin{array}{c}\text { Late Phase (15-30) } \\
(\mathbf{\%})\end{array}$ \\
\hline Control & $0.1 \mathrm{ml} / \mathrm{mouse}$ & $94.6 \pm 1.50$ & - & $41.2 \pm 1.15$ \\
\hline Diclofenac Sodium & 10 & $26.80 \pm 1.2 * * *$ & $71.67 \%$ & $1.60 \pm .24 * * *$ \\
\hline MEDP & 200 & $12 \pm 1.94 * * *$ & $87.31 \%$ & $2.60 \pm .67 * * *$ \\
\hline MEDP & 400 & $17.6 \pm 1.50 * * *$ & $81.39 \%$ & $1.60 \pm .24 * * *$ \\
\hline
\end{tabular}

Each value is expressed as the mean \pm SEM $(n=10)$. MEDP $=$ Methanol extract of Dioscera pentaphylla leaves. $* p<0.001$ compared with the control group (Dunnett's test).

\section{Discussion}

Our present study about the oral administration of MEDP elicits as a promising alternative candidate against central and peripheral painful condition. The earlier study has reported by the researchers that chemistry of $D$. pentaphylla contains new pharmacologically active agents, mainly to improve the treatment of pain. The hot plate and tail immersion tests are widely accepted methods for understanding the centrally acting antinociceptive activities. In our study, MEDP at 200 and $400 \mathrm{mg} / \mathrm{kg}$ doses exhibited antinociceptive effects in the hot plate and tail immersion tests by increasing hot plate latency as well as tail withdrawal response. The present findings endorsed that the central antinociceptive activity of MEDP may due to its effect on $\mu$-opioid receptors of spinal as well as the supraspinal system. MEDP containing compounds may minimize the activity of adenylyl cyclase which responsible for the $\mathrm{Ca}^{2+}$ influx at axon terminal of afferent nerve. The antinociceptive effect exerts by decreasing cAMP level, $\mathrm{K}^{+}$efflux, and subsequently hyperpolarization of the nerves.

The acetic acid-writhing test in mice extensively used for measuring the central and peripheral antinociceptive response to visceral pain. Intraperitoneal administration of acetic acid administration increase in the release of pro-inflammatory mediators such as cyclooxygenase (COX), prostaglandins (PGs), lipoxygenase (LOX), histamine, serotonin, bradykinin, substance $\mathrm{P}$, and cytokines (IL-1 $\beta$, IL-8, TNF- $\alpha$ ) in peripheral tissue fluid [16]. The expression of these mediators causes the excitation of primary afferent nociceptors entering in the dorsal horn of the spinal cord as well as the thalamus at central and peripheral nervous system. Our experimental findings also provide the supporting evidences about the use of $D$. pentaphylla in painful and inflammatory conditions.
Formalin-induced paw licking test, the antinociceptive property of MEDP observed through two distinct phases. MEDP activity observed as significant and dose-dependent at both neurogenic (early phase) and inflammatory (late phase) pain responses caused by formalin in mice. Sensory afferent fibers, specifically C-fibers (nociceptive nerve) stimulation release neuropeptides such as substance $P$ which induced neurogenic pain in case of early phase. Contrary, various inflammatory mediators like prostaglandins (PGs), histamine, bradykinin, and serotonin responsible for induced inflammatory pain in the late phase [17]. The earlier study reported that peripherally acting agents inhibit both first and second phases of the formalin response and that many centrally acting drugs only modulate the second phase of the formalin trial via spinal and supraspinal mechanisms. In our viewpoint, the finding data convinced us MEDP produces antinociception in both phases of the formalin-induced nociception test. The late phase response observed in the acetic acid-induced writhing test is due to the inhibition of the inflammatory mediators. Although thermal models revealed the centrally acting antinociceptive action of MEDP through the possible involvement of opioids receptors. As our expectation, MEDP expressing a quite different result. In case of the early phase, nerve ending directly involved the production of nociceptive responses. Nevertheless, it might be possible that MEDP produces less efficacy in the early phase of the formalin test. It is quite possible due to the different mechanisms with the thermal models where the antinociceptive activity of MEDP more prominent.

The phytochemical screening of MEDP revealed the presence of alkaloids, glycosides, and flavonoids, tannins, reducing sugar, carbohydrates, steroids and saponins. A considerable amount of alkaloids and flavonoids also quantified from the leaves of MEDP. Flavonoids and alkaloids interact directly with the prostaglandin system. 
Thereby, flavonoids and alkaloids are possible candidates for the antinociceptive agent. The entire experimental observation convinced us to assume that the antinociceptive effects of MEDP due to its high flavonoid contents. Additionally, flavonoids able to inhibit eicosanoid biosynthesis (such as prostaglandins) which has the involvements in various immunological responses and the end product of cyclooxygenase (COX) and lipoxygenase (LOX) pathway. Hence, the COX inhibitory of EETP may reduce the production of the chemical compounds (phospholipids) which is responsible for the prostaglandins synthesis and ultimately relieve the pain sensation.

\section{Conclusions}

These above findings convinced us MEDP possesses significant antinociceptive effects in mice model. The antinociceptive activity of MEDP is prominent in both Chemical-induced pain and Heat-induced pain models. We assumed that the antinociceptive activity of MEDP may involve in participation ATP-sensitive $\mathrm{K}^{+}$channel and cyclic adenosine monophosphate pathway at nociceptors. Further studies required to determine MEDP mechanism and inhibition pathway as well as isolate the potential compounds that may apply as the lead for drug development.

\section{List of Abbreviations}

MEDP $=$ methanolic extracts of Dioscorea pentaphylla ICDDR, B = International Center for Diarrheal Disease and Research, Bangladesh

$\mathrm{COX}=$ cyclooxygenase

$\mathrm{LOX}=$ lipoxygenase

$\mathrm{PG}=$ prostaglandins

cAMP $=$ cyclic Adenosine Monophosphate

\section{Declarations}

Ethics approval and consent to participate All the experimental mice were treated following the Ethical Principles and Guidelines for Scientific Experiments on Animals (1995) formulated by The Swiss Academy of Medical Sciences and the Swiss Academy of Sciences. The Institutional Animal Ethical Committee (SUB/IAEC/15.04) of Stamford University Bangladesh approved all experimental rules.

\section{Availability of Data and Material}

Not applicable

\section{Funding}

This research work did not have any particular funding. All the studies had been self-funded by author and co-authors.

\section{Competing Interests}

The authors report no conflicts of interest. The authors alone are responsible for the content and writing of the paper

\section{Authors' Contributions}

Md. Shahed-Al-Mahmud coordinated all laboratory experiments, analyzed and interpreted results. Md. Towhidul Islam did phytochemical analysis, Hot plate test, Tail immersion test, Acetic acid-induced writhing test, Formalin test and interpreted all experiments. Senior lecturer Anawara Begum supervised our research. Md. Shahed-Al-Mahmud did statistical analysis and drafted the manuscript. All authors read and approved the manuscript.

\section{Acknowledgements}

The authors are pleased to Professor Dr. Bidyut Kanti Datta, Chairman, Department of Pharmacy, Stamford University Bangladesh for his support to conduct the Pharmacology and Phytochemistry Laboratory.

\section{REFERENCES}

[1] Bhandari MR, Kawabata J: Organic acid, phenolic content and antioxidant activity of wild yam (Dioscorea spp.) tubers of Nepal. Food chemistry 2004, 88(2):163-168.

[2] Nguelefack TB, Dutra RC, Paszcuk AF, Andrade EL, Tapondjou LA, Calixto JB: Antinociceptive activities of the methanol extract of the bulbs of Dioscorea bulbifera L. var sativa in mice is dependent of NO-cGMPATP-sensitive-K+ channel activation. Journal of ethnopharmacology 2010, 128(3):567-574.

[3] Prakash G, Hosetti B: Investigation of Antimicrobial Properties of Doscorea pentaphylla from Mid Western Ghats, India. Scientific World 2010, 8(8):91-96.

[4] Poornima G, Ravishankar RV: In vitro propagation of wild yams, Dioscorea oppositifolia (Linn) and Dioscorea pentaphylla (Linn). African Journal of Biotechnology 2007, $6(20)$.

[5] Prakash G, Hosetti B: Bio-efficacy of Dioscorea pentaphylla from Midmid-western Ghats, India. Toxicology international 2012, 19(2):100.

[6] Prakash G, Hosetti B, Dhananjaya B: Antimutagenic effect 
of dioscorea pentaphylla on genotoxic effect induced by methyl methanesulfonate in the Drosophila wing spot test. Toxicology international 2014, 21(3):258.

[7] Horrocks M, Bedford S: Introduced Dioscorea spp. starch in Lapita and later deposits, Vao Island, Vanuatu. New Zealand Journal of Botany 2010, 48(3-4):179-183.

[8] Mbiantcha M, Kamanyi A, Teponno R, Tapondjou A, Watcho P, Nguelefack T: Analgesic and anti-inflammatory properties of extracts from the bulbils of Dioscorea bulbifera L. var sativa (Dioscoreaceae) in mice and rats. Evidence-Based Complementary and Alternative Medicine 2011, 2011.

[9] Shahed-Al-Mahmud M, Lina SMM: Evaluation of sedative and anxiolytic activities of methanol extract of leaves of Persicaria hydropiper in mice. Clinical Phytoscience 2017, 3(1):20.

[10] Eddy NB, Leimbach D: Synthetic analgesics. II. Dithienylbutenyl-and dithienylbutylamines. Journal of Pharmacology and Experimental Therapeutics 1953, 107(3):385-393.

[11] DEWEY WL, HARRIS LS, HOWES JF, NUITE JA: The effect of various neurohumoral modulators on the activity of morphine and the narcotic antagonists in the tail-flick and phenylquinone tests. Journal of Pharmacology and
Experimental Therapeutics 1970, 175(2):435-442.

[12] Gupta AK, Parasar D, Sagar A, Choudhary V, Chopra BS, Garg R, Khatri N: Analgesic and anti-inflammatory properties of gelsolin in acetic acid induced writhing, tail immersion and carrageenan induced paw edema in mice. PloS one 2015, 10(8): $\mathrm{e} 0135558$.

[13] Hajhashemi V, Sajjadi SE, Heshmati M: Anti-inflammatory and analgesic properties of Heracleum persicum essential oil and hydroalcoholic extract in animal models. Journal of ethnopharmacology 2009, 124(3):475-480.

[14] Hunskaar S, Hole K: The formalin test in mice: dissociation between inflammatory and non-inflammatory pain. Pain 1987, 30(1):103-114.

[15] Tjølsen A, Berge O-G, Hunskaar S, Rosland JH, Hole K: The formalin test: an evaluation of the method. Pain 1992, 51(1):5-17.

[16] Barbosa-Filho JM, Piuvezam MR, Moura MD, Silva MS, Lima KVB, da-Cunha EVL, Fechine IM, Takemura OS: Anti-inflammatory activity of alkaloids: A twenty-century review. Revista Brasileira de Farmacognosia 2006, 16(1):109-139.

[17] Geetha T, Varalakshmi P: Anti-inflammatory activity of lupeol and lupeol linoleate in rats. Journal of ethnopharmacology 2001, 76(1):77-80. 